\title{
Individual differences in fear extinction and anxiety-like behavior
}

\author{
Gabrielle King, Elliot Scott, Bronwyn M. Graham, and Rick Richardson
}

School of Psychology, The University of New South Wales, UNSW, Sydney, 2052, Australia

\begin{abstract}
There is growing appreciation for the substantial individual differences in the acquisition and inhibition of aversive associations, and the insights this might give into identifying individuals particularly vulnerable to stress and psychopathology. We examined whether animals that differed in rate of extinction (i.e., Fast versus Slow) were different in their response to an acute stress in adulthood or following a chronic stress that occurred either early or later in life. We found that Slow Extinguishers had significantly poorer extinction retention than Fast Extinguishers, but an acute stressor did not differentially affect anxiety-like behavior in the two groups. Further, while exposure to chronic stress in adulthood did not impact on the extinction phenotypes or anxiety-like behavior, exposure to chronic stress early in life affected both extinction retention and anxiety-like behavior. These findings have implications for the development of a more nuanced approach to identifying those most at risk of anxiety disorders.
\end{abstract}

Epidemiological evidence shows that most people who experience trauma recover while a smaller subset of individuals go on to develop some sort of psychopathology like anxiety and/or depression (e.g., Galea et al. 2005). For example, the U.S. National Comorbidity Survey Replication estimated the lifetime prevalence of post-traumatic stress disorder among adult Americans to be $6.8 \%$ (Kessler et al. 2005). Even among populations characterized by the experience of multiple traumas, such as rescue workers and refugees, prevalence rates for post-traumatic stress disorder are estimated at just 30\%-40\% (Steel et al. 2009; Berger et al. 2012). Such findings have led to considerable interest in what determines, and what can be used to predict, resilience versus susceptibility to trauma.

Research with animal models can, and have, contributed to this effort. That is, there is growing appreciation for the substantial individual differences in both the acquisition of aversive associations as well as the inhibition of those associations. For example, using a large sample of outbred rats Bush et al. (2007) observed striking individual differences in the rate of learning an aversive association that was associated with the strength of memory expression in subsequent tests. In that study rats were given five pairings of a white noise conditioned stimulus (CS) with a footshock unconditioned stimulus (US), and CS-elicited freezing during conditioning was used to classify animals as either a "Fast" conditioning phenotype (top 20\%) or a "Slow" conditioning phenotype (bottom 20\%). Those animals with a Fast conditioning phenotype had significantly higher levels of CS-elicited freezing when later exposed to the CS alone in both the conditioning context and a novel context compared with animals with a Slow conditioning phenotype. Differences in the expression of aversive associations to both a discrete CS and to a context have also been observed using a single conditioning trial (Graham and Richardson 2016).

There is also evidence that there are individual differences in the inhibition of learned aversive associations. For example, Bush et al. (2007) first conditioned rats with a white noise CS and then gave them extinction training, which consisted of 20 presentations of the CS in the absence of the US. The amount of

Corresponding author: g.king@unsw.edu.au

Article is online at http://www.learnmem.org/cgi/doi/10.1101/Im.045021. 117.
CS-elicited freezing was used to classify animals into either a "Fast" extinction phenotype (top 20\%) or a "Slow" extinction phenotype (bottom 20\%). When tested for extinction retention the following day animals with a Fast extinction phenotype exhibited better extinction retention than those with a Slow extinction phenotype. Interestingly, rate of conditioning was not a good predictor of the rate of extinction. That is, animals with a Fast or Slow extinction phenotype exhibited no differences in the rate of acquisition during conditioning or in the levels of CS-elicited freezing at the start of extinction training.

Consistent with Bush et al. (2007), Reznikov et al. (2015) found that animals with a Fast extinction phenotype exhibited better extinction retention than those with a Slow rate of extinction. Furthermore, Reznikov et al. (2015) found that animals with a Slow rate of extinction displayed more anxiety-like behavior than animals with a Fast rate of extinction when tested on the elevated plus maze (EPM) after the extinction retention test. However, if animals were tested on the EPM prior to conditioning then no such differences were observed. Reznikov et al. (2015) suggested that the stress induced by the conditioning procedure, which involved shock, revealed an anxious temperament in animals with a Slow rate of extinction. These findings suggest impairments in the extinction of learned aversive associations might be a useful model for identifying stress-vulnerable individuals. Given it is generally accepted that stress plays a causal role in activating or exacerbating psychopathologies such as anxiety and depression (e.g., Schumm et al. 2005; Leonardo and Hen 2008), we were interested in further exploring whether Fast and Slow extinction phenotypes differed in their response to stress. There is a large body of evidence suggesting that stress has different behavioral and physiological effects depending on whether it is acute or chronic and the time at which it is experienced (i.e., early in life versus later in life). Thus, we examined whether the Fast and Slow Extinction phenotypes differed in their response to an acute stress in adulthood (Experiment 1), following a chronic stress

\footnotetext{
(C) 2017 King et al. This article is distributed exclusively by Cold Spring Harbor Laboratory Press for the first 12 months after the full-issue publication date (see http://learnmem.cshlp.org/site/misc/terms.xhtml). After 12 months, it is available under a Creative Commons License (Attribution-NonCommercial 4.0 International), as described at http://creativecommons.org/licenses/by$\mathrm{nc} / 4.0 /$.
} 
early in life (Experiment 2), and following a chronic stress later in life (Experiment 3).

One limitation with the past work examining naturally occurring individual differences in the rate of extinction is that it has involved giving all animals the same number of extinction trials. As such, during extinction training those animals with a Fast rate of extinction receive more trials where they display low levels of freezing than those animals with a Slow rate of extinction. Indeed, Reznikov et al. (2015) had significant differences in freezing levels between Fast and Slow extinguishers at the end of extinction training (i.e., $2 \%-15 \%$ versus $70 \%-90 \%$, respectively). Therefore, it is unclear whether the observed differences in extinction retention and anxiety-like behavior reflected the rate at which these animals extinguished or their levels of fear at the end of extinction training. To address this issue, in the present study we gave extinction trials until an animal reached a predetermined criterion such that all animals had equivalent low levels of freezing at the end of extinction training, regardless of their rate of extinction.

\section{Results}

Experiment 1. Fast and Slow extinction phenotypes differ in extinction retention but not anxiety-like behavior before or after an acute stressor

In this experiment, all animals were first tested on the EPM, which is frequently used to measure anxiety-like behavior in rodents, and then on the following day given repeated pairings of a white noise CS with a shock US. On the day following these pairings, all animals were exposed to the CS by itself (i.e., extinction training) until levels of CS-elicited freezing had reduced to a predetermined criterion. Based on the number of trials taken to reach the criterion animals were designated as either Fast or Slow extinguishers. The next day animals were tested for extinction retention, and $\sim 24 \mathrm{~h}$ later retested on the EPM. Past work has shown that exposure to an acute stress, such as a forced swim stress, increases anxiety-like behavior (i.e., more time spent in the closed arms of the EPM; Hogg 1996), and so we also asked whether Fast and Slow extinguishers differed in terms of their response to an acute stressor. As such, on the day after the second EPM test animals were exposed to $2 \mathrm{~min}$ of a forced swim stressor and were then tested again on the EPM $1 \mathrm{~min}, 2 \mathrm{~h}$, and $10 \mathrm{~d}$ later. Performance at the 1-min interval would reveal whether the Fast and Slow extinguishers differed in their immediate response to the acute stressor. The 2-h test was included in order to determine if the two groups differed in their rate of recovery from the acute stressor while the $10 \mathrm{~d}$ interval was included because some research has shown that the effects of an acute stressor can increase over time (Mitra et al. 2005). The question here was whether any such increase might differ between Fast versus Slow extinguishers.

There were low levels of baseline freezing prior to conditioning, extinction, and test (all means $<4.6 \%$, all SEMS $<1.9 \%$; largest $t_{(30)}=1.89, P=0.08$ ). Those animals subsequently classified as being either Fast or Slow extinguishers exhibited comparable levels, and rate of increase, of CS-elicited freezing across the repeated pairings of the CS and US (see Fig. 1, panel A). Statistical analysis of these data yielded an effect of Trial $\left(F_{(4,30)}=112.26, P<0.001\right)$; the effect of Group, and the Group-by-Trial interaction, was not significant $(F s<1.0)$. There were individual differences in the number of blocks required for animals to reach criterion during extinction training (see Fig. 2). Across the extinction training trials there was a decrease in levels of CS-elicited freezing (see Fig. 1, panel B), with those levels being significantly less on the last block of extinction in comparison to the first block of extinction $\left(F_{(1,30)}=264.85, P<0.001\right)$. Although both groups exhibited high levels of CS-elicited freezing on the first block of extinction training trials, the Fast extinguishers had slightly lower levels compared with the Slow extinguishers $\left(t_{(30)}=2.01, P=0.053\right.$, 95\% CI: $[-26.21,-0.17])$. The groups did not differ on levels of freezing on the last block of extinction training $\left(t_{(30)}=0.32, P=\right.$ $0.75,95 \% \mathrm{CI}:[-7.10,5.18])$, which is not surprising given that both were extinguished to a common criterion. When tested for extinction retention (see Fig. 1, panel C) animals that had a Slow rate of extinction the day before had higher levels of CS-elicited freezing than animals that had a Fast rate of extinction $\left(t_{(29.99)}=2.88, P<0.01,95 \% \mathrm{CI}:[-50.53,-8.60]\right)$. That is, consistent with Bush et al. (2007) and Reznikov et al. (2015) rats with a Fast rate of extinction displayed better extinction retention (i.e., less CS-elicited freezing) compared with rats with a Slow rate of extinction. However, it is important to note that unlike those previous studies, in the current study animals with a Fast and Slow extinction phenotype were given different numbers of trials such that both were expressing the same low levels of CS-elicited freezing for the same number of trials at the end of extinction training.

There were no group differences in anxiety-like behavior between animals classified as being either Fast or Slow extinguishers, averaging across EPM performance prior to and after conditioning $\left(F_{(1,30)}=1.75, P=0.20\right.$; see Fig. 3$)$, nor was the main effect or interaction involving Time (i.e., prior to or after conditioning) significant $(F \mathrm{~s}<1.0)$. The acute swim stress affected

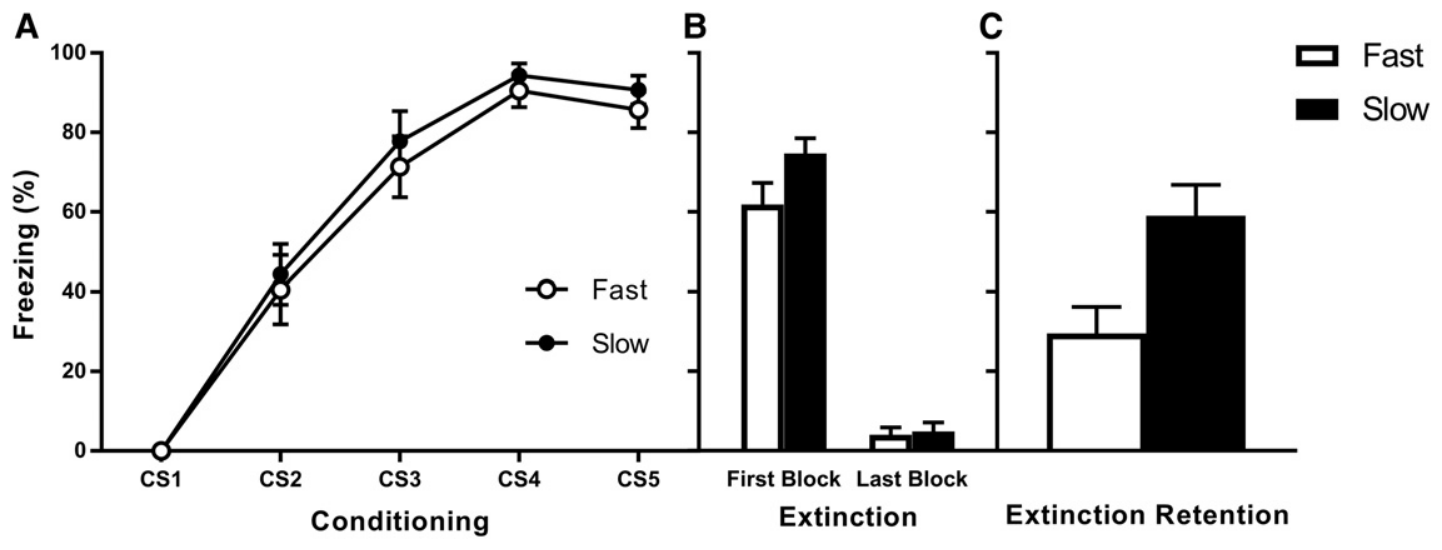

Figure 1. CS-elicited freezing in Experiment 1. (A) Mean ( \pm SEM) CS-elicited freezing during Conditioning, (B) Extinction (First Block and Last Block), and $(C)$ Extinction Retention Test. 


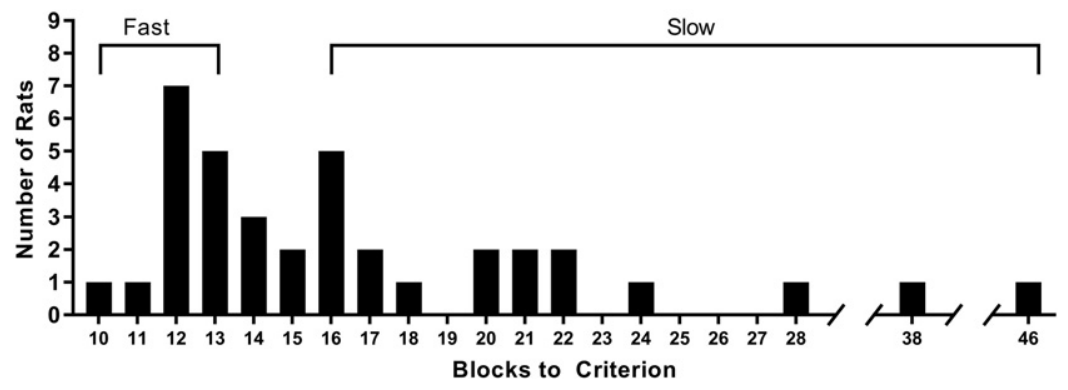

Figure 2. Number of Blocks required for animals to reach criterion during extinction training in Experiment 1.

EPM performance, as indicated by a significant effect of Time (i.e., 1-min, 2-h, or 10-d delay; $F_{(1.26,37.73)}=18.02, P<0.001$; see Fig. $3)$, reflecting a marked increase in time spent in the closed arms of the EPM compared with baseline levels at the test 1 min later. However, time in the closed arms returned to baseline levels at the 2-h interval and the 10-d interval. The effect of the stressor was comparable for the Fast and Slow extinguishers, with neither the effect of Group nor the Group-by-Time interaction statistically significant (both $F \mathrm{~s}<1.0$ ). Taken together, these findings show that the Fast and Slow extinguishers do not differ on at least one common measure of anxiety either (1) before or (2) after conditioning/extinction, or (3) when tested at three time points following an acute swim stress.

\section{Experiment 2. Effects of early-life maternal separation} on the extinction phenotypes and on anxiety-like behavior in adulthood

In this experiment, we examined the effects of early-life stress on the extinction phenotypes as well as on a measure of anxiety-like behavior. We also examined whether a "two-hit effect" might further reveal underlying vulnerability following maternal separation (MS) (e.g., Eiland and McEwen 2012; Uchida et al. 2010). That is, the question here was whether MS affected the expression of the Fast and Slow extinction phenotypes in terms of extinction retention, baseline anxiety-like behavior, or anxiety-like behavior following an acute stressor. The EPM, conditioning and extinction, and swim stress protocols used in the previous experiment were used again to examine these questions.

There were low levels of baseline freezing prior to conditioning, extinction, and test for all groups (all means $<12.5 \%$, all SEMS $<4.0 \%$; largest $\left.F_{(1,31)}=2.61, P=0.12\right)$. During condition- ing levels of CS-elicited freezing increased across trials $\left(F_{(2.80,86.93)}=\right.$ 111.31, $P<0.001$; see Fig. 4 , panel A). Neither the effect of subsequent rate of extinction (i.e., Fast versus Slow) nor any interactions involving this factor were statistically significant (largest $\left.F_{(2.80,86.93)}=1.62, P=0.19\right)$. In contrast, the effect of Rearing condition was statistically significant $\left(F_{(1,31)}=6.67, \quad P=\right.$ 0.015). Follow-up $t$-tests showed that this was due to MS animals having significantly lower levels of CS-elicited freezing than SR animals on the last conditioning trial $\left(t_{(33)}=3.96, P=0.001\right.$, $95 \%$ CI: $[12.09,39.09])$; the two groups did not differ on any other conditioning trial (largest $\left.t_{(33)}=1.45, P=0.16\right)$.

There were individual differences in the number of blocks required for animals to reach criterion during extinction training (see Fig. 5). As expected, CS-elicited freezing levels decreased from the first block to the last block of extinction $\left(F_{(1,31)}=\right.$ 232.30, $P<0.001)$. While there was a difference between MS and SR animals on the last conditioning trial, during extinction training there was no significant effect of rearing condition $\left(F_{(1,31)}=2.36, P=0.13\right.$; see Fig. 4 , panel B). Further, there was no effect of rate of extinction (i.e., Fast versus Slow; $F_{(1,31)}=$ $3.98, P=0.06)$, nor were any of the interaction effects during extinction significant (largest $F_{(1,31)}=1.79, P=0.19$ ). When tested for extinction retention (see Fig. 4, panel C) there were significant main effects for rearing condition $\left(F_{(1,31)}=9.84, P<0.01\right)$ and rate of extinction $\left(F_{(1,31)}=36.19, P<0.001\right)$. The rearing condition by rate of extinction interaction was also significant $\left(F_{(1,31)}=5.07, P=0.03\right)$, such that MS animals with a Slow rate of extinction displayed significantly poorer extinction retention compared with both MS rats that had a Fast rate of extinction $\left(t_{(14)}=5.59, P<0.001,95 \% \mathrm{CI}:[-84.21,-37.53]\right)$ and SR rats with a Slow rate of extinction $\left(t_{(14)}=3.16, P<0.01,95 \%\right.$ CI: $[-66.62,-12.71])$. Consistent with Experiment 1, the Slow extinguishers in the SR condition had poorer extinction retention than did the Fast extinguishers $\left(t_{(10.41)}=2.95, P=0.01,95 \% \mathrm{CI}\right.$ : $[-48.58,-6.87])$.

Averaging across rate of extinction and EPM performance prior to and after conditioning, MS animals displayed heightened anxiety-like behavior compared with SR animals $\left(F_{(1,30)}=9.38\right.$, $P<0.01$; see Fig. 6). Consistent with Experiment 1 the main effect and interactions involving Time (i.e., prior to or after conditioning) were not significant (largest $F_{(1,30)}=1.66, P=0.21$ ). There
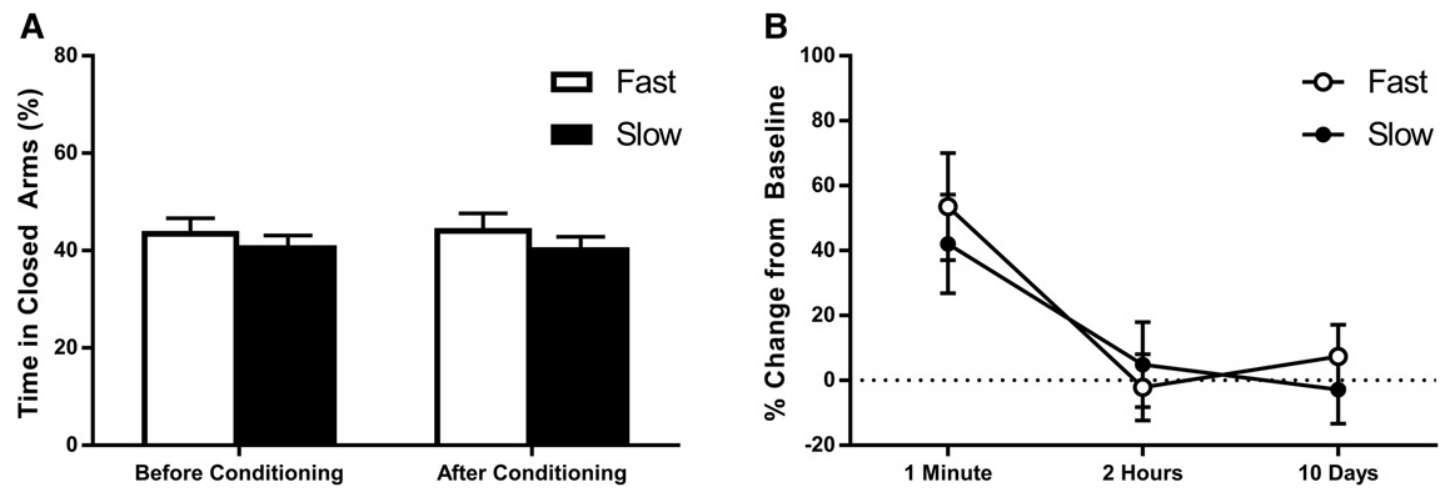

Figure 3. Performance on the EPM in Experiment 1. $(A)$ Mean $( \pm$ SEM) percentage of time spent in the Closed Arms of the EPM before conditioning and after conditioning. (B) Mean Change from Baseline (\%) ( \pm SEM) of time in the Closed Arms (\%) at the 1-min, 2-h, and 10-d delay after the 2-min forced swim stress. Baseline was time in the Closed Arms of the EPM after conditioning. 


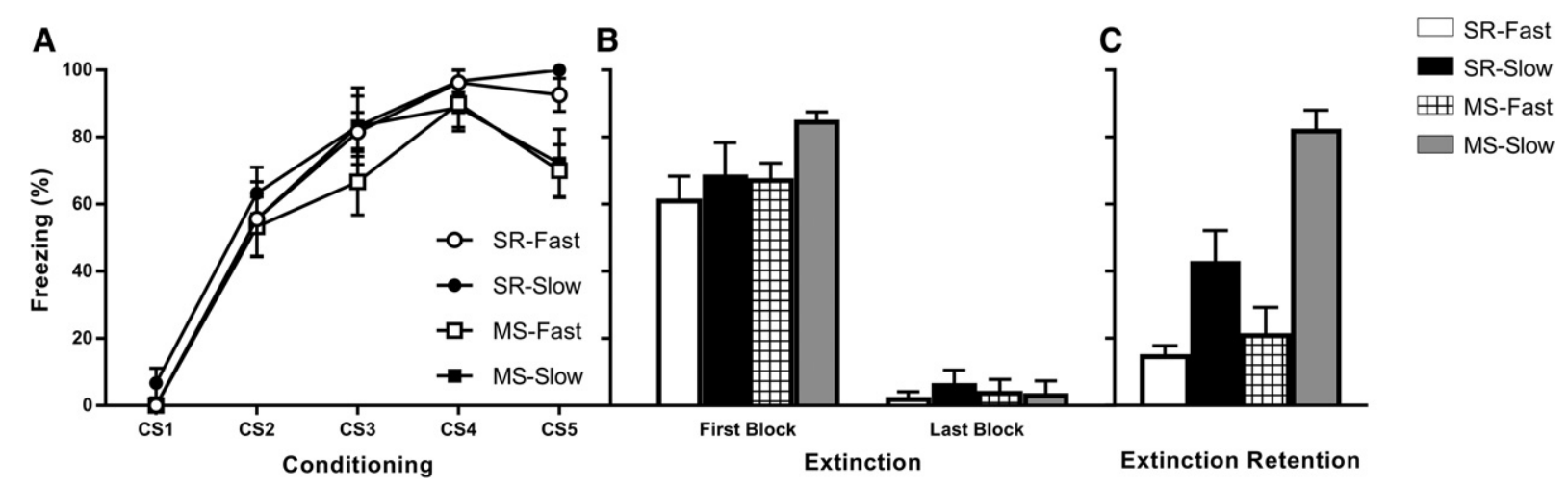

Figure 4. Levels of CS-elicited freezing in Experiment 2. (A) Mean ( \pm SEM) CS-elicited freezing during Conditioning, (B) Extinction (First Block and Last Block), and (C) Extinction Retention Test for SR and MS animals, Fast and Slow extinction phenotypes.

was no significant effect of rate of extinction on anxiety-like behavior averaging across EPM tests prior to and after conditioning $(F<1.0)$, nor were any of the rearing condition or rate of extinction interaction effects significant (largest $F_{(1,30)}=1.66, P=$ $0.21)$. The acute swim stress affected EPM performance, as indicated by a significant effect of Time (i.e., 1-min, 2-h, or 10-d delay; $\left.F_{(1.29,39.95)}=37.29, P<0.001\right)$, reflecting a marked increase in time spent in the closed arms of the EPM compared with baseline levels at the test 1-min later. However, time spent in the closed arms returned to baseline levels at the 2-h interval and the 10-d interval. Averaging across time points, the effect of the stressor was comparable for all groups $(F \mathrm{~s}<1.0$; largest interaction $\left.F_{(1.29,39.95)}=2.32, P=0.13\right)$. Taken together these findings suggest that, relative to SR rats, MS rats with a Slow rate of extinction display poor extinction retention and increased baseline anxietylike behavior, however do not differ in their response to, or recovery from, an acute stressor.

\section{Experiment 3. Effects of exposure to a chronic stressor in adulthood on the extinction phenotypes and on anxiety-like behavior}

In the final experiment in this study we examined whether a chronic stressor in adulthood had the same effects on the extinction phenotypes and anxiety-related behavior as was observed following an early-life stressor in Experiment 2. A chronic stressor that is commonly used in adult rats is exposure to the stressrelated hormone corticosterone (CORT). As such, in this experiment animals were exposed to either 3 wk of CORT or Vehicle in their drinking water before being tested for individual differences in extinction and anxiety-like behavior using the same procedures and design as was used in Experiment 2.

There were low levels of baseline freezing prior to conditioning, extinction, and test (all means $<10.5 \%$, all SEMS $<5.3 \%$ ). While there were no significant group or interaction effects for baseline freezing during conditioning and extinction (largest $F_{(1,42)}=3.32$, $P=0.08)$, at test animals in Fast extinction group had significantly lower levels of baseline freezing than animals in the Slow extinction group $\left(F_{(1,42)}=5.08\right.$, $P=0.03)$. However, it should be noted that baseline levels of freezing were very low in both groups $\left(M_{\text {Fast }}=1.54, M_{\text {Slow }}=8.00\right)$. Nonetheless, the effect of including baseline freezing as a covariate in the analysis of CS-elicited freezing at the extinction retention test was examined. During conditioning, there was an increase in CS-elicited freezing across training trials $\left(F_{(2.61,109.48)}=185.78, P<0.001\right)$ which was comparable across groups (largest between group effect $F_{(1,42)}=1.55, P=0.22$; see Fig. 7 , panel A). There were individual differences in the number of blocks required for animals to reach criterion during extinction training (see Fig. 8). During extinction, CS-elicited freezing decreased from the first block to the last block $\left(F_{(1,42)}=609.18, P<0.001\right)$. There was no effect of CORT-exposure on freezing during extinction $(F<1.0)$, however there was a significant effect of rate of extinction $\left(F_{(1,42)}=5.36\right.$, $P=0.03)$. That is, while Fast and Slow extinguishers had comparable levels of freezing during the first block of extinction $\left(t_{(44)}=\right.$ $1.14, P=0.26,95 \% \mathrm{CI}:[-15.87,4.41])$, Fast extinguishers had lower levels of freezing during the last block of extinction $\left(t_{(44)}=2.50, P=0.02\right.$, 95\% CI: $\left.[-15.17,-1.50]\right)$. However, it should be noted that due to the low levels of freezing in both groups in the last block of extinction $\left(M_{\text {Fast }}=2.12, M_{\text {Slow }}=\right.$ 10.45), this difference is unlikely to be meaningful. Regardless, we examined CS-elicited freezing during the extinction retention test with freezing levels during the final block of extinction retention included as a covariate.

Consistent with Experiments 1 and 2, when tested for extinction retention the following day the rats with a Fast rate of extinction displayed significantly lower levels of CS-elicited freezing than did rats with a Slow rate of extinction $\left(F_{(1,42)}=15.01, P<\right.$

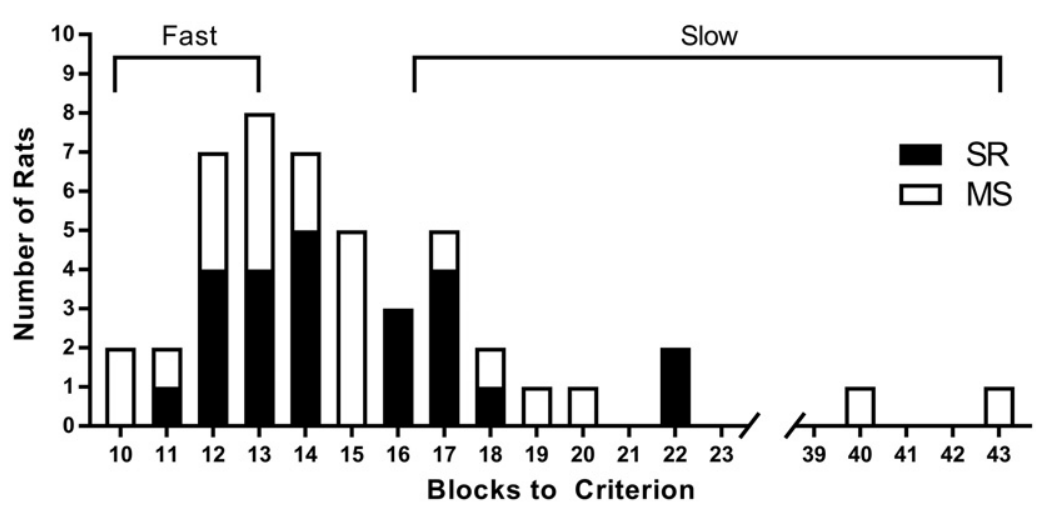

Figure 5. Number of Blocks required for animals to reach criterion during extinction training in Experiment 2 for SR and MS rats. 

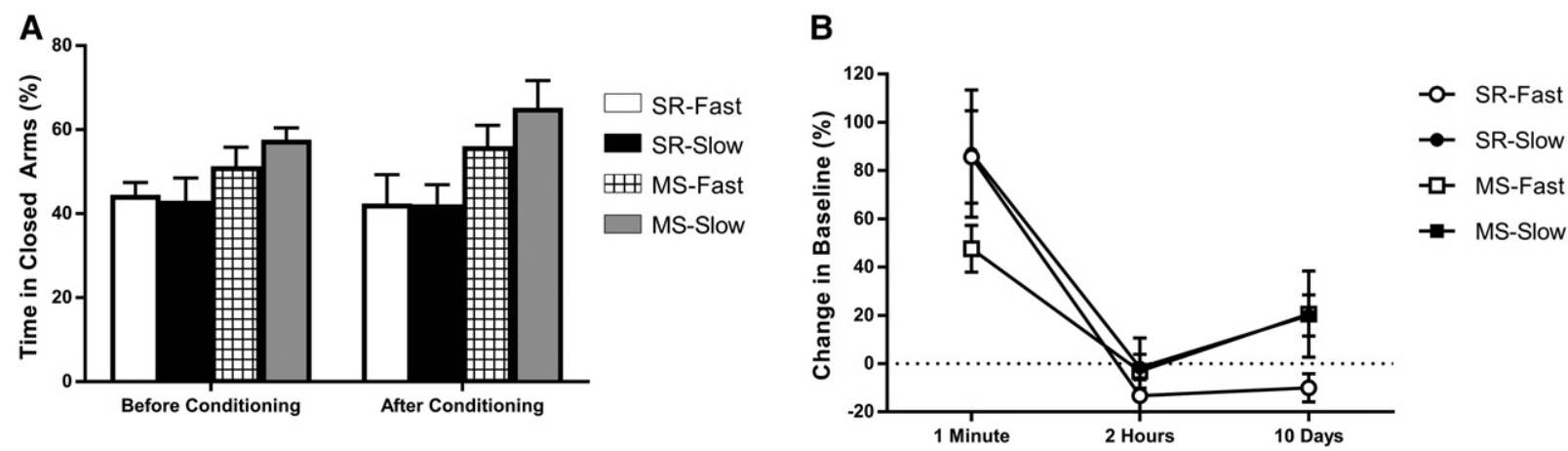

Figure 6. Performance on the EPM for SR and MS animals, Fast and Slow extinction phenotypes in Experiment 2. ( $A$ ) Mean ( \pm SEM) percentage of time spent in the Closed Arms of the EPM prior to conditioning and after conditioning. (B) Mean Change from Baseline (\%) $( \pm$ SEM) of time in the Closed Arms (\%) at the 1-min, 2-h, and 10-d delay after the 2-min forced swim stress. Baseline was time in the Closed Arms of the EPM after conditioning.

0.001). There was no main effect of CORT and no significant CORT by rate of extinction interaction (both $F \mathrm{~s}<1.0$ ). This pattern of results was still observed if baseline freezing or freezing during the last block of extinction was included as a covariate. So, unlike chronic stress early in life (i.e., MS), chronic stress in adulthood did not differentially affect extinction retention for rats with a Fast or Slow rate of extinction.

There were no differences in anxiety-like behavior between any of the groups when averaging across EPM performance prior to and after conditioning (largest $F_{(1,42)}=1.98, P=0.17$; see Fig. 9). Consistent with Experiments 1 and 2 the main effect and interactions involving Time (i.e., prior to or after conditioning) were not significant (all $F \mathrm{~s}<1.0$ ). The acute swim stress affected EPM performance, as indicated by a significant effect of Time $\left(F_{(2,42)}=82.82, P<0.001\right)$, reflecting a marked increase in time spent in the closed arms of the EPM compared with baseline levels at the test 1-min later. However, time spent in the closed arms returned to baseline levels at the 2-h and the 10-d interval. Averaging across time points, the effect of the stressor was comparable for all groups (largest group main effect $F_{(1,42)}=2.11, P=$ 0.15 ; largest interaction $\left.F_{(2,42)}=2.71, P=0.07\right)$. Taken together these findings suggest that exposure to CORT in adulthood does not differentially affect Fast versus Slow extinguishers on extinction retention or anxiety-like behavior.

To determine whether the orally administered CORT had any effect, animals were sacrificed $48-72 \mathrm{~h}$ after the final EPM test and their adrenal glands were extracted and weighed. As can be seen in Table 1 , there were no differences in body weight between groups, nor did rate of extinction affect the average adrenal gland weight. However, the average weight of the adrenal glands from CORT-exposed animals was significantly less than those of the VEHICLE-exposed animals $\left(t_{(44)}=2.26, P=0.02,95 \%\right.$ CI: [0.35, 6.07]). There were no significant differences in average fluid consumption between CORT-exposed and VEHICLE-exposed animals largest $F_{(19,95)}=1.09, P=0.375 ; M_{\mathrm{CORT}}=312.88 \mathrm{~mL} / \mathrm{box}$, $M_{\mathrm{VEH}}=325.35 \mathrm{~mL} /$ box $)$.

\section{Discussion}

In the present study, we explored individual differences in the inhibition of learned aversive associations (i.e., Fast versus Slow extinguishers), with a particular focus on the effects of stress on these phenotypes. Specifically, we examined whether the Fast and Slow Extinction phenotypes differed in their response to an acute stress in adulthood (Experiment 1), following a chronic stress early in life (Experiment 2), and following a chronic stress later in life (Experiment 3).

Consistent with Bush et al. (2007) and Reznikov et al. (2015), across all three experiments we found that Slow Extinguishers had significantly poorer extinction retention than Fast Extinguishers. However, it is important to note that unlike those previous studies, in the current study animals with a Fast and Slow extinction phenotype were given different numbers of trials in order to ensure that both were expressing the same low levels of CS-elicited freezing at the end of extinction training and that both experienced the same number of trials with this lower level of freezing. Importantly, the effect of rate of extinction on extinction

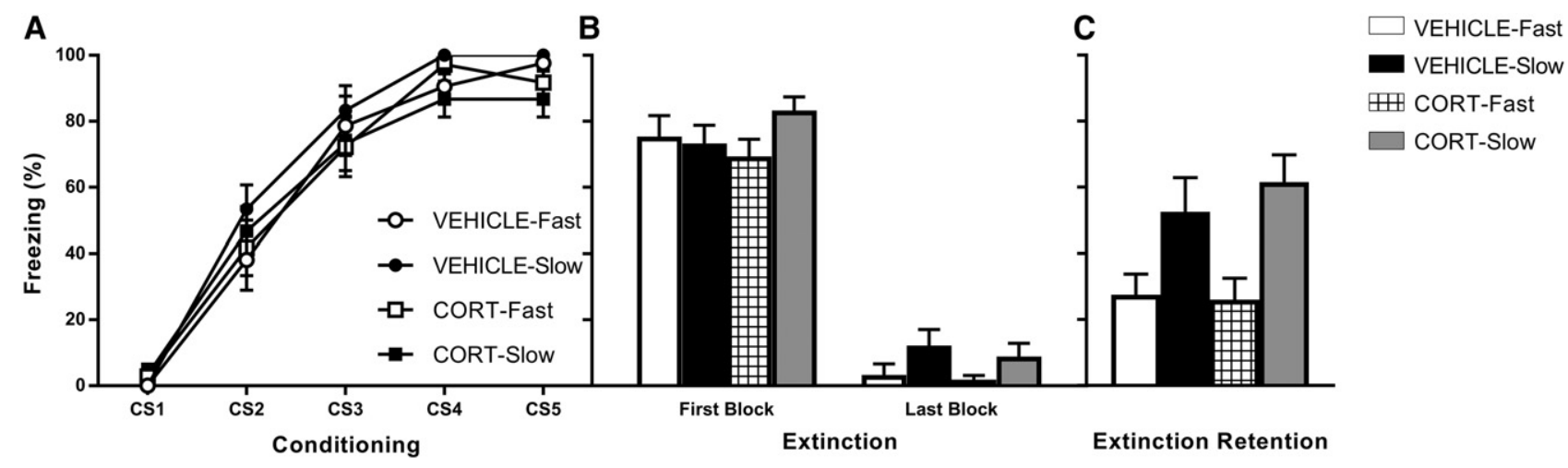

Figure 7. Levels of CS-elicited freezing in Experiment 3. (A) Mean ( \pm SEM) CS-elicited freezing during Conditioning, (B) Extinction (First Block and Last Block), and (C) Extinction Retention Test for VEHICLE and CORT-exposed animals, Fast and Slow extinction phenotypes. 


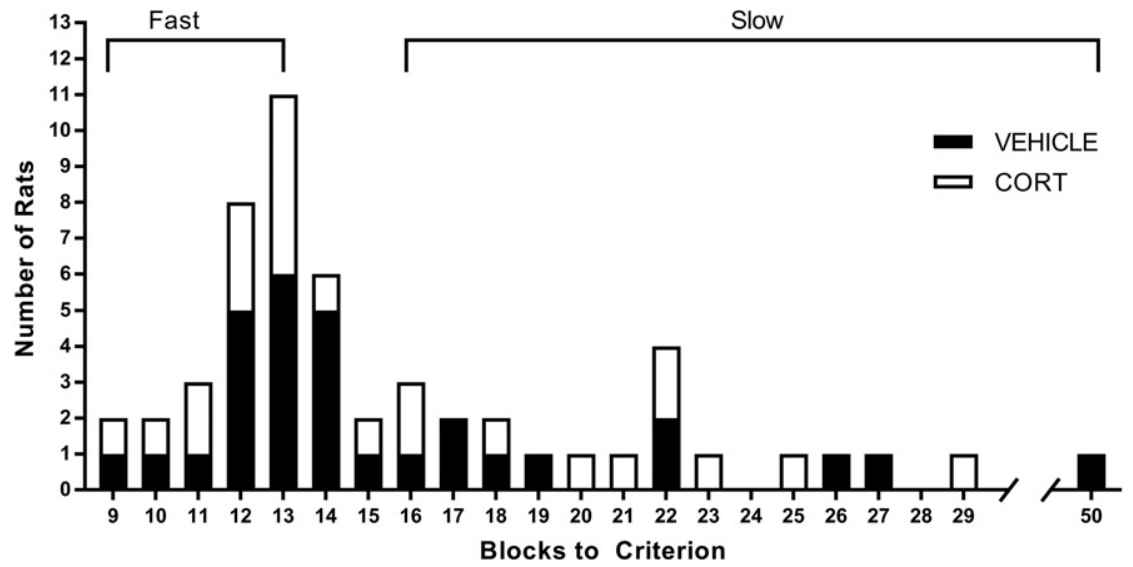

Figure 8. Number of Blocks required for animals to reach criterion during extinction training in Experiment 3 for VEHICLE and CORT rats.

retention cannot be attributed to differences in conditioning or extinction; there were no group differences during conditioning, and while there was a marginal difference between Fast and Slow Extinguishers during the first block of extinction in Experiment 1, in Experiments 2 and 3 there was no significant difference. Similarly, there was no difference between groups in the last block of extinction in Experiments 1 and 2, and while there was a slight difference between Fast and Slow Extinguishers in the last block of extinction in Experiment 3 this had no effect on the pattern of results when included as a covariate.

Across all three experiments we found no effect of Fast and Slow Extinction phenotypes on the EPM either before or after conditioning; the latter result is in contrast to those reported by Reznikov et al. (2015). Specifically, Reznikov et al. (2015) suggested that a difference in EPM performance between Fast and Slow Extinction phenotypes emerged as a result of the stress of conditioning. However, even following an acute stressor (i.e., the forced swim stress) we found no differences between Fast and Slow Extinction phenotypes on EPM performance. While the forced swim stress increased anxiety-like behavior 1-min later, this occurred equally for the Fast and Slow Extinction phenotypes in all three experiments. Further, in all three experiments anxietylike behavior returned to baseline $2 \mathrm{~h}$ and $10 \mathrm{~d}$ after the acute swim stress. As at the 1-min test interval, the effect of the stressor was comparable across all groups at these longer intervals. That is, there was no effect of Fast and Slow Extinction phenotypes on EPM performance following the forced swim stress. EPM tests. In contrast, in the current study all animals were extinguished to the same low level of freezing, such that there was no residual fear that could be generalized to a different test setting (i.e., the EPM).

While in contrast to the findings reported by Reznikov et al. (2015), our findings are conceptually similar to those reported by Bush et al. (2007). That is, we did not find any evidence of a relationship between the Fast and Slow Extinction phenotypes with anxiety (as measured by performance on the EPM), in three experiments and across multiple test conditions. Similarly, Bush et al. (2007) reported that the Extinction phenotype was orthogonal to the Conditioning phenotype. In other words, their results showed that the Fast and Slow extinguishers acquired the noise-shock association at the same rate, indicating that they did not differ in their susceptibility to acquiring aversive associations. A similar effect was observed in the current study. Taken together these findings suggest that the rate at which an individual learns to extinguish an aversive association seems to be orthogonal to both acquiring such associations and anxiety. This finding has implications for our understanding of anxiety disorders, which can be conceptualized as being due to an increased likelihood of developing extreme negative reactions (i.e., a Fast conditioning phenotype) and/or reduced ability to recover following a negative reaction (i.e., a Slow extinction phenotype; Yehuda et al. 2006). The current findings suggest that rather than a general vulnerability to anxiety (i.e., an individual that displays a Fast conditioning phenotype, a Slow extinction phenotype, and high
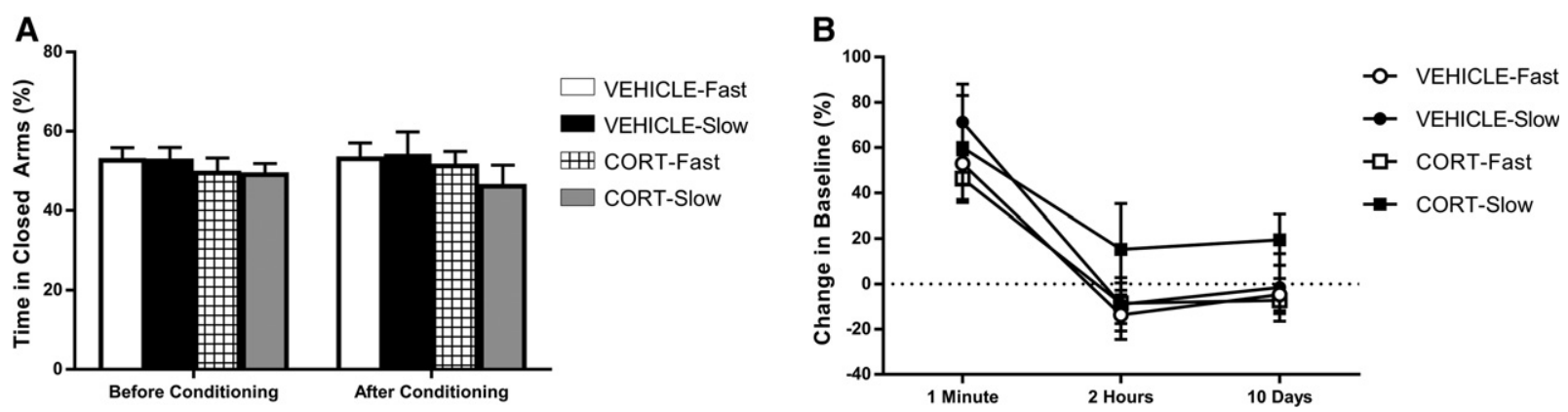

Figure 9. Performance on the EPM for VEHICLE and CORT animals, Fast and Slow extinction phenotypes in Experiment 3. ( $A$ ) Mean ( \pm SEM) percentage of time spent in the Closed Arms of the EPM prior to conditioning and after conditioning. (B) Mean Change from Baseline (\%) ( \pm SEM) of time in the Closed Arms (\%) at the 1-min, 2-h, and 10-d delay after the 2-min forced swim stress. Baseline was time in the Closed Arms of the EPM after conditioning. 
Table 1. Mean ( \pm SEM) body weight ( $\mathrm{g})$ and average adrenal gland weight (mg) for Fast and Slow extinction phenotypes given Vehicle or CORT in their drinking water in Experiment 3

\begin{tabular}{lccccc} 
& \multicolumn{2}{c}{ VEHICLE } & & \multicolumn{2}{c}{ CORT } \\
\cline { 2 - 3 } \cline { 5 - 6 } & \multicolumn{1}{c}{ Fast } & Slow & & Fast & Slow \\
\hline Body weight $(\mathrm{g})$ & $489(11.8)$ & $488(14.5)$ & & $475(9.1)$ & $470(16.1)$ \\
Adrenal gland weight $(\mathrm{mg})^{\mathrm{a}}$ & $27.3(1.4)$ & $29.1(1.1)$ & & $25.6(1.7)$ & $23.8(1.1)$ \\
\hline
\end{tabular}

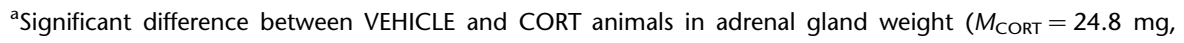
$\left.M_{\mathrm{VEH}}=28.01 \mathrm{mg} ; t_{(44)}=-2.26, P=0.02\right)$.

baseline anxiety-like behavior), there are different mechanisms by which an individual can develop an anxiety disorder. Further, this suggests that if these mechanisms can be identified, different approaches to treating anxiety might be indicated.

Finding reliable predictors for these phenotypes may have implications for identifying those at risk of developing anxiety disorders, and will be an interesting issue for future research to explore. For instance, variations in endogenous fibroblast growth factor-2 (FGF2) have previously been shown to be associated with vulnerability or resilience to expressing aversive associations (Graham and Richardson 2016; Walters et al. 2016). Given there is conservation in the neural and molecular mechanisms underpinning conditioning and extinction (Quirk and Mueller 2008; Graham and Milad 2011; Graham and Richardson 2011) it is possible FGF2 might also predict extinction phenotypes. However, with the apparent orthogonality of the conditioning and extinction phenotypes (Bush et al. 2007; the present study) this might not be the case.

Another issue for future research to explore is whether the Fast and Slow extinction phenotypes observed here for inhibiting aversive associations are similarly observed for other tasks. Given it has been suggested that there is overlap in the neural circuits involved in aversive and appetitive tasks (Peters et al. 2009), it would be interesting to examine whether Fast and Slow extinction phenotypes are observed for tasks involving inhibiting appetitive associations, and what the concordance rate is. For example, do animals that have a Slow extinction phenotype for inhibiting aversive associations also have a Slow extinction phenotype for inhibiting appetitive associations?

The current experiments also looked at the effects of chronic stress, both early in life and later in life, on the Fast and Slow Extinction phenotypes. Interestingly, early life stress, modeled by maternal separation during infancy (MS), resulted in poorer extinction retention only for Slow Extinguishers: MS-Fast Extinguishers were comparable to SR-Fast Extinguishers but MS-Slow Extinguishers had significantly poorer extinction retention than SR-Slow Extinguishers. In contrast, chronic stress in adulthood, modeled by CORT in the drinking water, did not affect extinction retention for either Extinction phenotype. That is, there was an interaction between chronic stress and extinction phenotype only if the chronic stress was experienced early in life.

We found that MS animals displayed more anxiety-like behavior than SR animals, as indicated by more time in the closed arms of the EPM (Experiment 2), replicating past results (e.g., Vallée et al. 1997; Kalinichev et al. 2002; Lupien et al. 2009). Consistent with past findings (Andreatini and Leite 1994; Kalynchuk et al. 2004; Gregus et al. 2005), we did not observe an effect of CORT exposure in adulthood on anxiety-like behavior (Experiment 3). As previously mentioned, while the forced swim stress increased anxiety-like behavior 1 min later, this occurred equally for the Fast and Slow Extinction phenotypes in all three experiments. In addition, chronic stress, either early in life (Experiment 2) or in adulthood (Experiment 3) did not impact on this result. Further, in all three experiments anxiety-like behav- ior returned to baseline $2 \mathrm{~h}$ and $10 \mathrm{~d}$ after the acute swim stress. As at the 1-min test interval, the effect of the stressor was comparable across all groups at these longer intervals. That is, there was no effect of Fast and Slow Extinction phenotypes (Experiments 1-3), chronic stress early in life (Experiment 2), or chronic stress in adulthood (Experiment 3 ) at these intervals, showing that recovery from the acute swim stress did not differ across these various groups.

In the current experiments we found that while exposure to chronic stress in adulthood did not impact on either the extinction phenotypes or on anxiety-like behavior (Experiment 3), exposure to chronic stress early in life affected both extinction retention and anxiety-related behavior (Experiment 2). It should be noted that the effects of stress during development and adulthood cannot be equated, so it could be the case that the lack of effect of chronic stress in adulthood is because it is "milder" than maternal separation. However, these findings are consistent with a large body of work demonstrating that the effects of stress on the brain and behavior varies across the lifespan (for review, see Lupien et al. 2009). For instance, Conrad et al. (1999) found that, in contrast to the long-lasting effects of chronic stress early in life, morphological changes in the hippocampus following chronic stress in adulthood were reversed within $10 \mathrm{~d}$ of the termination of the stressor. In contrast, stress early in life leads to a reprogramming of the HPA axis, morphological and functional changes in the brain, and increased anxiety-like behavior, effects that last into adulthood (for review, see Kaufman et al. 2000; Teicher et al. 2003). Interestingly, the results of the current study suggest that the experience of early-life stress is only associated with vulnerability to anxiety if the individual is also a Slow Extinguisher; MS-Fast animals showed comparable extinction retention to SR-Fast animals. Given early life stress is considered a risk factor for developing psychopathology (Heim and Nemeroff 2001) these findings have important implications for developing a more nuanced approach to identifying those most at risk of anxiety disorders.

\section{Materials and Methods}

\section{Subjects}

Experimentally naïve male Sprague-Dawley rats either bred at the School of Psychology at The University of New South Wales (UNSW) or purchased from the Animal Resources Centre (ARC) Western Australia were used (the breeders were purchased from this source as well). Rats were housed in groups of eight in plastic boxes (63 cm long $\times 42 \mathrm{~cm}$ wide $\times 22 \mathrm{~cm}$ high) with a wire lid. Animals were maintained on a 12-h light-dark cycle (lights on a 07:00 h), and food and water was available ad libitum. Animals were treated in accordance with The Australian Code of Practice for the Care and Use of Animals for Scientific Purposes (8th Edition, 2013) and all procedures were approved by the Animal Care and Ethics Committee at UNSW.

\section{Apparatus}

Conditioning, extinction, and test sessions were conducted in experimental chambers located within separate wood cabinets in order to minimize external noise and visual stimulation. Each chamber was fitted with a ventilation fan that produced a low and constant background noise $(50 \mathrm{~dB}$, measured by a digital sound level meter, Tenma model \#72-942) and a mounted infrared camera was used to record the animal's behavior during the experiments. Chambers were cleaned with tap water between each session. 
Conditioning occurred in a set of two identical rectangular chambers $(13.5 \mathrm{~cm}$ long $\times 9 \mathrm{~cm}$ wide $\times 9 \mathrm{~cm}$ high), referred to as context A. The floor and side walls consisted of 3-mm stainless steel rods set $1-\mathrm{cm}$ apart. The front wall, rear wall, and ceiling consisted of clear Plexiglas. A custom-built, constant-current shock generator could deliver shock through the chamber floor. Two high-frequency speakers were mounted on either side of the chamber. These chambers had no source of illumination apart from infrared lighting.

Rats received extinction training and the extinction retention test in Context B. The chambers in this context differed to those in Context A in both size and visual characteristics. The chambers in Context $\mathrm{B}$ consisted of a set of two identical rectangular chambers $(30 \mathrm{~cm}$ long $\times 30 \mathrm{~cm}$ wide $\times 23 \mathrm{~cm}$ high), with two opposing side walls consisting of $2-\mathrm{cm}$ wide vertical black and white stripes. The ceiling, floor, and back wall consisted of clear Plexiglas. Two high-frequency speakers were mounted in the ceiling of the chamber. A white LED light provided illumination $(\sim 12$ lux; as measured by Digitech light meter QM1587) in Context B.

The Elevated Plus Maze (EPM) consisted of a plus-shaped wood platform with two open arms (50 cm long $\times 12 \mathrm{~cm}$ wide) and two closed arms (50 cm long $\times 12 \mathrm{~cm}$ wide). The walls of the open arms were $1-\mathrm{cm}$ high while the walls of the closed arms were $39-\mathrm{cm}$ high. The EPM was located in a brightly lit room (265 cm long $\times 185 \mathrm{~cm}$ wide $\times 260 \mathrm{~cm}$ high; 510 lux) and was wiped clean with $70 \%$ ethanol solution between each animal to remove any scent trails.

\section{Procedures}

\section{Conditioning}

Following a 2-min adaptation period (baseline), the CS (white noise, 8-dB above background noise levels) was presented for 10 sec and coterminated with the foot shock US (0.4 mA, $1 \mathrm{sec})$. Animals received five CS-US pairings, and were returned to their home cage $\sim 20 \mathrm{sec}$ after the final CS-US pairing.

\section{Extinction training}

One day after conditioning, animals were given extinction training. Following a 2-min adaption period (baseline), the CS was repeatedly presented (10-sec duration) with a 10 -sec inter-trial interval (ITI). Extinction training terminated once an animal reached a criterion of $<35 \%$ freezing for eight out of nine consecutive blocks of CS presentations, where one block was three 10-sec $\mathrm{CS}$ presentations. Animals were returned to their home cage $\sim 20$ sec after the final CS presentation.

The number of CS blocks required to reach extinction criterion was used to classify animals as having either a "Fast" or "Slow" rate of extinction. Rather than using a median-split procedure to categorize animals as Fast or Slow extinguishers, rats that reached criterion on $\leq 13$ CS blocks were classified as the Fast extinction phenotype, and those that reached criterion on $\geq 16$ CS Blocks were classified as the Slow extinction phenotype. Rats that reached extinction criterion on 14 or 15 CS Blocks were excluded from subsequent analyses (5 rats from Experiment 1, 12 rats from Experiment 2, and 8 rats from Experiment 3). This procedure was followed to maximally differentiate the two phenotypes and to also avoid the situation where, depending on what the median value was in any given experiment, an intermediate number of trials to reach criterion could be categorized as being Fast in one experiment but Slow in another. Three rats were excluded from subsequent analysis as they did not display CS-elicited freezing during either of the first two blocks of extinction (i.e., did not condition; 1 rat from each experiment), and three rats were excluded because they did not reach the extinction criterion within 50 blocks (two rats from Experiment 1, and one rat from Experiment 3).

\section{Extinction retention test}

The day after extinction training animals were tested for extinction retention. Test consisted of a 1-min adaption period (baseline) followed by a 2-min presentation of the CS.

\section{Elevated plus maze (EPM)}

Each rat was placed in the center of the EPM facing an open arm and allowed to freely explore the maze for $5 \mathrm{~min}$. Arm entry was defined as the front two paws entering the arm. Each rat was scored on time in the closed arms, which was then converted to a percentage of the total exploration time (i.e., $5 \mathrm{~min}$ ).

\section{Forced swim stress}

A white bucket ( $37 \mathrm{~cm}$ wide $\times 35 \mathrm{~cm}$ high) filled with $28 \mathrm{~cm}$ of water $\left(20^{\circ} \mathrm{C}-23^{\circ} \mathrm{C}\right)$ was used for the Forced Swim Stress. The level of water was sufficiently deep so that the rats could not touch the bottom of the bucket with their back paws. Animals were placed into the water for $2 \mathrm{~min}$, and then thoroughly towel-dried.

\section{Maternal separation}

From post-natal days 2-14 litters in the MS condition were separated from their mothers (dams) and placed in an incubator for 3 -h per day commencing between 0800 and 1200 . The incubator was maintained at $\sim 25^{\circ} \mathrm{C}$ (see Callaghan and Richardson 2011). Throughout the separation period dams remained in their home cage. Rats in the SR condition were maintained, as a litter, with their mother on these days. All rats were weaned, and housed in groups of $2-8$, on post-natal days $22-25$.

\section{CORT administration}

Subjects in the CORT condition were given $200 \mu \mathrm{g} / \mathrm{mL}$ of CORT (11B, 21-dihydroxy-4-pregnene-3, 20-dione; Sigma-Aldrich, Sydney, Australia) dissolved in water; $5 \%$ ethanol was added to the water for the CORT to completely dissolve. Subjects in the vehicle/control condition were given water with 5\% ethanol. Animals were exposed to altered drinking water for $21 \mathrm{~d}$. This procedure is consistent with previous experiments that have exposed rats to CORT (e.g., Den et al. 2014).

\section{Adrenal gland extraction}

Animals were weighed and then asphyxiated with $\mathrm{CO}_{2}$. Once euthanized, the left and right adrenal glands were extracted and weighed to the nearest $10^{-4} \mathrm{~g}$ (as measured by Mettler Toledo XS204 balance).

\section{Data analysis}

Freezing, a species-specific fear response defined as the absence of any movement except breathing (Fanselow 1980), was used as the measure of the learned aversive association. Baseline and CS-elicited freezing was scored using a time sampling procedure, whereby the animal was judged as either freezing or not-freezing every $3 \mathrm{sec}$. The number of freezing observations was converted into a percentage of overall observations. A random sample of $30 \%$ of the extinction retention and EPM data was cross-scored by a second observer who was blind to experimental group. Inter-rater reliability was high across all experiments (all $r>$ 0.96).

Statistical analysis was conducted using SPSS Version 22, with values of $P<0.05$ considered significant. Across all the experiments, Pre-CS freezing was analyzed using independent $t$-tests or ANOVA where appropriate. Conditioning, extinction training, extinction retention, and EPM data were analyzed using ANOVA, with the Greenhouse-Geisser correction used if the assumption of sphericity was violated (as indicated by Mauchly's Test of Sphericity). Significant effects were followed up post hoc with independent samples $t$-tests, with correction for unequal variances if the assumption of homogeneity of variances was violated (as indicated by Levene's Test for Equality of Variances).

In Experiment 2 the data for 1 rat from the SR-Fast group on the first EPM test was lost due to experimenter error. 


\section{Acknowledgments}

This research was submitted by E.S. as his Honours thesis for a Bachelor of Psychological Science degree. G.K. is supported by an Australian Postgraduate Award, and this research was supported by grants from the National Health and Medical Research Council (APP1031688), and the Australian Research Council (DP150104835) to R.R.

\section{References}

Andreatini R, Leite JR. 1994. The effect of corticosterone in rats submitted to the elevated plus-maze and to pentylenetetrazol-induced convulsions. Prog Neuropsychopharmacol Biol Psychiatry 18: 1333-1347.

Berger W, Coutinho ESF, Figueira I, Marques-Portella C, Luz MP, Neylan TC, Marmar CR, Mendlowicz MV. 2012. Rescuers at risk: a systematic review and meta-regression analysis of the worldwide current prevalence and correlates of PTSD in rescue workers. Soc Psychiatry Psychiatr Epidemiol 47: $1001-1011$.

Bush DE, Sotres-Bayon F, LeDoux JE. 2007. Individual differences in fear: isolating fear reactivity and fear recovery phenotypes. J Trauma Stress 20: $413-422$.

Callaghan BL, Richardson R. 2011. Maternal separation results in early emergence of adult-like fear and extinction learning in infant rats. Behav Neurosci 125: 20-28.

Conrad CD, LeDoux JE, Magariños AM, McEwen BS. 1999. Repeated restraint stress facilitates fear conditioning independently of causing hippocampal CA3 dendritic atrophy. Behav Neurosci 113: 902-913.

Den ML, Altmann SR, Richardson R. 2014. A comparison of the short-and long-term effects of corticosterone exposure on extinction in adolescence versus adulthood. Behav Neurosci 128: 722-735.

Eiland L, McEwen BS. 2012. Early life stress followed by subsequent adult chronic stress potentiates anxiety and blunts hippocampal structural remodeling. Hippocampus 22: 82-91.

Fanselow MS. 1980. Signaled shock-free periods and preference for signaled shock. J Exp Psychol Anim Behav Process 6: 65-80.

File SE, Mabbutt PS, Hitchcott PK. 1990. Characterisation of the phenomenon of "one-trial tolerance" to the anxiolytic effect of chlordiazepoxide in the elevated plus-maze. Psychopharmacology 102: 98-101.

File SE, Zangrossi H Jr, Viana M, Graeff FG. 1993. Trial 2 in the elevated plus-maze: a different form of fear? Psychopharmacology 111: 491-494.

Galea S, Nandi A, Vlahov D. 2005. The epidemiology of post-traumatic stress disorder after disasters. Epidemiol Rev 27: 78-91.

Graham BM, Milad MR. 2011. The study of fear extinction: implications for anxiety disorders. Am J Psychiatry 168: 1255-1265.

Graham B, Richardson R. 2011. Memory of fearful events: the role of fibroblast growth factor-2 in fear acquisition and extinction. Neuroscience 189: 156-169.

Graham BM, Richardson R. 2016. Individual differences in the expression of conditioned fear are associated with endogenous fibroblast growth factor 2. Learn Mem 23: 42-45.

Gregus A, Wintink AJ, Davis AC, Kalynchuk LE. 2005. Effect of repeated corticosterone injections and restraint stress on anxiety and depression-like behavior in male rats. Behav Brain Res 156: 105-114.

Heim C, Nemeroff CB. 2001. The role of childhood trauma in the neurobiology of mood and anxiety disorders: preclinical and clinical studies. Biol Psychiatry 49: 1023-1039.

Hogg S. 1996. A review of the validity and variability of the elevated plus-maze as an animal model of anxiety. Pharmacol Biochem Behav 54: 21-30.

Kalinichev M, Easterling KW, Plotsky PM, Holtzman SG. 2002. Long-lasting changes in stress-induced corticosterone response and anxiety-like behaviors as a consequence of neonatal maternal separation in LongEvans rats. Pharmacol Biochem Behav 73: 131-140.

Kalynchuk LE, Gregus A, Boudreau D, Perrot-Sinal TS. 2004. Corticosterone increases depression-like behavior, with some effects on predator odor-induced defensive behavior, in male and female rats. Behav Neurosci 118: 1365.

Kaufman J, Plotsky PM, Nemeroff CB, Charney DS. 2000. Effects of early adverse experiences on brain structure and function: clinical implications. Biol Psychiatry 48: 778-790.

Kessler RC, Berglund P, Demler O, Jin R, Merikangas KR, Walters EE. 2005. Lifetime prevalence and age-of-onset distributions of DSM-IV disorders in the National Comorbidity Survey Replication. Arch Gen Psychiatry 62: 593-602.

Leonardo ED, Hen R. 2008. Anxiety as a developmental disorder. Neuropsychopharmacology 33: 134-140.

Lupien SJ, McEwen BS, Gunnar MR, Heim C. 2009. Effects of stress throughout the lifespan on the brain, behaviour and cognition. Nat Rev Neurosci 10: 434-445.

Mitra R, Jadhav S, McEwen BS, Vyas A, Chattarji S. 2005. Stress duration modulates the spatiotemporal patterns of spine formation in the basolateral amygdala. Proc Natl Acad Sci 102: 9371-9376.

Peters J, Kalivas PW, Quirk GJ. 2009. Extinction circuits for fear and addiction overlap in prefrontal cortex. Learn Mem 16: 279-288.

Quirk GJ, Mueller D. 2008. Neural mechanisms of extinction learning and retrieval. Neuropsychopharmacology 33: 56-72.

Reznikov R, Diwan M, Nobrega JN, Hamani C. 2015. Towards a better preclinical model of PTSD: characterizing animals with weak extinction, maladaptive stress responses and low plasma corticosterone. J Psychiatr Res 61: 158-165.

Schumm JA, Stines LR, Hobfoll SE, Jackson AP. 2005. The double-barreled burden of child abuse and current stressful circumstances on adult women: the kindling effect of early traumatic experience. I Trauma Stress 18: 467-476.

Steel Z, Chey T, Silove D, Marnane C, Bryant RA, Van Ommeren M. 2009. Association of torture and other potentially traumatic events with mental health outcomes among populations exposed to mass conflict and displacement: a systematic review and meta-analysis. JAMA 302: 537-549.

Teicher MH, Andersen SL, Polcari A, Anderson CM, Navalta CP, Kim DM. 2003. The neurobiological consequences of early stress and childhood maltreatment. Neurosci Biobehav Rev 27: 33-44.

Treit D, Menard J, Royan C. 1993. Anxiogenic stimuli in the elevated plus-maze. Pharmacol Biochem Behav 44: 463-469.

Uchida S, Hara K, Kobayashi A, Funato H, Hobara T, Otsuki K, Yamagata H, McEwen BS, Watanabe Y. 2010. Early life stress enhances behavioral vulnerability to stress through the activation of REST4-mediated gene transcription in the medial prefrontal cortex of rodents. J Neurosci 30: 15007-15018.

Vallée M, Mayo W, Dellu F, Le Moal M, Simon H, Maccari S. 1997. Prenatal stress induces high anxiety and postnatal handling induces low anxiety in adult offspring: correlation with stress-induced corticosterone secretion. J Neurosci 17: 2626-2636.

Walters E, Richardson R, Graham BM. 2016. Individual differences in conditioned fear expression are associated with enduring differences in endogenous Fibroblast Growth Factor-2 and hippocampal-mediated memory performance. Neurobiol Learn Mem 134: 248-255.

Yehuda R, Flory JD, Southwick S, Charney DS. 2006. Developing an agenda for translational studies of resilience and vulnerability following trauma exposure. Ann N Y Acad Sci 1071: 379-396.

Received January 17, 2017; accepted in revised form March 3, 2017. 


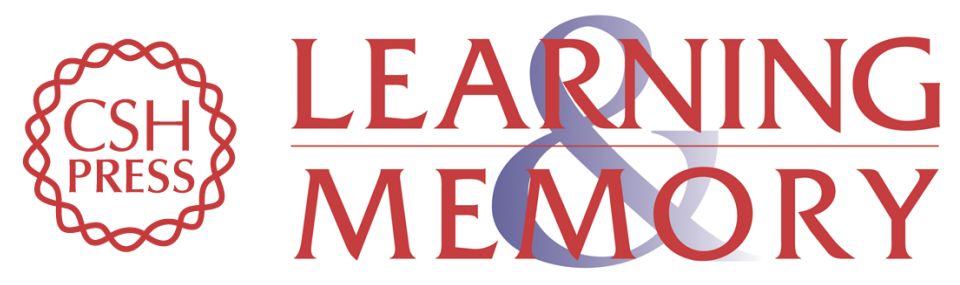

\title{
Individual differences in fear extinction and anxiety-like behavior
}

\author{
Gabrielle King, Elliot Scott, Bronwyn M. Graham, et al.
}

Learn. Mem. 2017, 24:

Access the most recent version at doi:10.1101/Im.045021.117

References This article cites 35 articles, 4 of which can be accessed free at: http://learnmem.cshlp.org/content/24/5/182.full.html\#ref-list-1

Creative This article is distributed exclusively by Cold Spring Harbor Laboratory Press for the Commons License first 12 months after the full-issue publication date (see http://learnmem.cshlp.org/site/misc/terms.xhtml). After 12 months, it is available under a Creative Commons License (Attribution-NonCommercial 4.0 International), as described at http://creativecommons.org/licenses/by-nc/4.0/.

Email Alerting Receive free email alerts when new articles cite this article - sign up in the box at the Service top right corner of the article or click here. 